\title{
Single Site Cobalt Substitution in 2D Molybdenum Carbide (MXene) Enhances Catalytic Activity in the Hydrogen Evolution Reaction
}

Denis A. Kuznetsov, ${ }^{\dagger}$ Zixuan Chen ${ }^{\dagger}$ Priyank V. Kumar, ${ }^{\dagger}$ Athanasia Tsoukalou, ${ }^{\dagger}$ Agnieszka Kierzkowska, ${ }^{\dagger}$ Paula M. Abdala, ${ }^{\dagger}$ Olga V. Safonova, ${ }^{\#}$ Alexey Fedorov ${ }^{*}{ }^{\dagger}$ and Christoph R. Müller*†

${ }^{\dagger}$ ETH Zürich, Department of Mechanical and Process Engineering, CH 8092 Zürich, Switzerland

$\$$ University of New South Wales, School of Chemical Engineering, Sydney, New South Wales 2052, Australia

\# Paul Scherrer Institute, CH-5232 Villigen, Switzerland

Corresponding Authors:

*A.F.: fedoroal@ethz.ch

*C.R.M.: muelchri@ethz.ch 


\section{GENERAL EXPERIMENTAL}

Synthesis. $\beta-\mathrm{Mo}_{2} \mathrm{C}$ : Co. Ammonium heptamolybdate tetrahydrate $\left(\mathrm{NH}_{4}\right)_{6} \mathrm{Mo}_{7} \mathrm{O}_{24} \cdot 4 \mathrm{H}_{2} \mathrm{O}(5.0 \mathrm{~g}$, $99 \%$, Alfa Aesar) and cobalt nitrate hexahydrate $\mathrm{Co}\left(\mathrm{NO}_{3}\right)_{2} \cdot 6 \mathrm{H}_{2} \mathrm{O}(1.237 \mathrm{~g}$, $99 \%$, Acros Organics), molar ratio 1:0.15, were dissolved in $150 \mathrm{ml}$ of deionized water to produce a clear red solution. Subsequently, the solvent was evaporated by heating at $100{ }^{\circ} \mathrm{C}$ in an oven. The dry residue was ground in a mortar to yield a fine pink powder which was carburized in a quartz reactor

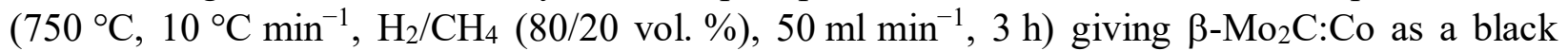
solid.

$\mathrm{Mo}_{2} \mathrm{Ga}_{2} \mathrm{C}$ : Co. Preparation of $\mathrm{Mo}_{2} \mathrm{Ga}_{2} \mathrm{C}$ was conducted according to the reported literature procedure. ${ }^{1}$ As-synthesized $\beta-\mathrm{Mo}_{2} \mathrm{C}$ :Co $(2 \mathrm{~g})$ was homogeneously mixed with metallic Ga (99.99\%, Acros Organics), molar ratio $\beta-\mathrm{Mo}_{2} \mathrm{C}: \mathrm{Co}: \mathrm{Ga}=1: 12(8.20 \mathrm{~g} \mathrm{Ga})$, in a mortar. This amount of $\mathrm{Ga}$ is required to ensure homogenous mixing and formation of a paste-like material. The obtained paste was transferred to a quartz tube, evacuated to $c a$. $10^{-5} \mathrm{mbar}$, flame-sealed under dynamic vacuum and annealed for $48 \mathrm{~h}$ at $850{ }^{\circ} \mathrm{C}\left(10^{\circ} \mathrm{C} \mathrm{min}-1\right)$. The as-prepared material was first stirred in aqueous HF ( $50 \mathrm{~mL}, \geq 48 \%$, Sigma Aldrich) for $72 \mathrm{~h}$ at room temperature to remove excess unreacted metallic Ga and metallic Co remaining from the synthesis of $\beta-\mathrm{Mo}_{2} \mathrm{C}: \mathrm{Co}$. The obtained solid residue was washed with DI water until a pH of $c a$. 6 was reached. Drying in air at $80{ }^{\circ} \mathrm{C}$ for $12 \mathrm{~h}$ produced the desired $\mathrm{Mo}_{2} \mathrm{Ga}_{2} \mathrm{C}$ :Co phase.

$\mathrm{Mo}_{2} C T_{x}$ : Co. The MXene phase, $\mathrm{Mo}_{2} \mathrm{C} T_{x}$ :Co, was synthesized by etching Ga from $\mathrm{Mo}_{2} \mathrm{Ga}_{2} \mathrm{C}$ :Co following a recently reported literature protocol. ${ }^{1} \mathrm{Mo}_{2} \mathrm{Ga}_{2} \mathrm{C}: \mathrm{Co}(1 \mathrm{~g})$ and $50 \mathrm{~mL}$ of $\geq 48 \% \mathrm{HF}$ were stirred at $140{ }^{\circ} \mathrm{C}$ for 7 days in a sealed Teflon lined stainless steel Parr autoclave placed in a sand bath. Important: experiments with concentrated HF at high temperatures as used in this work required extra care and were conducted in an HF-dedicated fume hood at the specialized Toxlab of ETH Zürich. The resulting suspension was centrifuged at $5000 \mathrm{rpm}$ for $3 \mathrm{~min}$ to separate the solid product, which was repeatedly washed with DI water until a pH of washings reached ca. 6 . The solid obtained was dried in air at $80{ }^{\circ} \mathrm{C}$ for $12 \mathrm{~h}$.

Characterization. X-ray powder diffraction (XRD) data were collected on a PANalytical Empyrean X-ray diffractometer equipped with a Bragg-Brentano HD mirror and operated at $45 \mathrm{kV}$ and $40 \mathrm{~mA}$ using $\mathrm{CuK} \alpha$ radiation $(\lambda=1.5418 \AA)$. The Le Bail fitting of the XRD patterns ${ }^{2}$ was preformed using Fullprof software. ${ }^{3}$ Scanning electron microscopy (SEM) measurements were performed on a FEI Magellan 400 FEG microscope. Prior to imaging, the samples were sputter coated with an ca. $5 \mathrm{~nm}$ thick layer of PtPd (CCU-010 Metal Sputter Coater Safematic). TEM imaging was performed using a FEI Talos F200X microscope equipped with a high-brightness field-emission gun, a high-angle annular dark field (HAADF) detector, and a large collection-angle EDX detector. The operation voltage of the instrument was set to $200 \mathrm{kV}$ in scanning transmission electron microscopy (STEM) mode. To prepare the sample for TEM measurements, dried powder of $\mathrm{Mo}_{2} \mathrm{CT}_{x}$ : $\mathrm{Co}(100 \mathrm{mg})$ was dispersed in a $10 \%$ aqueous solution of tetrabutylammonium hydroxide (TBAOH) (Sigma Aldrich) $(5 \mathrm{ml})$ and stirred overnight. ${ }^{4}$ The solid residue was separated from the solution by centrifugation and washed 3 times with water $(20 \mathrm{ml})$ and 3 times with ethanol $(20 \mathrm{ml})$ to remove excess $\mathrm{TBAOH}$. The powder was then sonicated with $5 \mathrm{ml}$ of ethanol for $1 \mathrm{~h}$ in an ice-cooled ultrasonic bath. The dark purple colloidal solution was separated from the solid by centrifugation at $3500 \mathrm{rpm}$ for $30 \mathrm{~min}$. This solution was drop cast onto $\mathrm{Cu}$ grids coated with carbon for TEM measurements. X-ray photoelectron spectroscopy (XPS) measurements were conducted on a Sigma 2 instrument (Thermo Fisher Scientific) equipped with an UHV chamber (non-monochromatic $200 \mathrm{~W}$ Al Ka source, a hemispherical analyzer, and a seven 
channel electron multiplier). The analyzer-to-source angle was $50^{\circ}$, while the emission angle was $0^{\circ}$. A pass energy of $50 \mathrm{eV}$ and $25 \mathrm{eV}$ was set for the survey and the narrow scans, respectively. The C $1 \mathrm{~s}$ peak of adventitious carbon was set at $284.8 \mathrm{eV}$ to compensate for any charge induced shifts. XPS data were analyzed with the CasaXPS software. Elemental Analysis measurements were performed by the Mikroanalytisches Labor Pascher, Germany.

X-ray absorption spectroscopy (XAS) measurements (Co K-edge) were performed at the SuperXAS beamline of the Swiss Light Source (SLS) (PSI, Villigen, Switzerland). The incident photon beam provided by a $2.9 \mathrm{~T}$ superbend magnet was selected by a Si (111) channel-cut monochromator. The rejection of higher harmonics and focusing were achieved by a Si-coated collimating mirror at $2.5 \mathrm{mrad}$ and a rhodium-coated torroidal mirror at $2.5 \mathrm{mrad}$. Co K-edge XAS data for the reference samples $\left(\mathrm{Co}, \mathrm{CoO}, \mathrm{Co}_{3} \mathrm{O}_{4}\right)$ were collected in transmission mode from pellets of the corresponding materials composed of the optimized amount of sample mixed with cellulose. For Co-doped carbides, the Co K-edge XAS spectra were collected on pure materials in fluorescence mode using a five-element silicon drift detector (SGX). XAS data processing was performed using the Athena software and EXAFS fitting was performed with the Artemis software (Demeter 0.9.25 software package). For EXAFS data analysis, the spectra were converted to the photoelectron wave vector $\mathrm{k}\left(\AA^{-1}\right)$. The resulting $\chi(\mathrm{k})$ functions were $\mathrm{k}^{2}$ weighted and Fourier transformed over the $2.7-10 \AA^{-1}$ range.

The samples of $\mathrm{Mo}_{2} \mathrm{CT}_{x}$ :Co after HER experiments for XAS, XPS and SEM investigation were prepared by attaching a pellet of $\mathrm{Mo}_{2} \mathrm{C} T_{x}: \mathrm{Co}(9 \mathrm{~mm}$ diameter, $c a .70 \mathrm{mg})$ to a graphene paper $(120$ $\mu \mathrm{m}$ thickness, Sigma Aldrich) with a conductive carbon glue (Ted Pella). The electrode was held at $-0.25 \mathrm{~V}$ vs. RHE for $15 \mathrm{~min}$. Intensive $\mathrm{H}_{2}$ bubbles formation was observed during experiment. The pellet was carefully rinsed with DI water to remove $\mathrm{H}_{2} \mathrm{SO}_{4}$ and air-dried.

Electrochemical measurements. HER measurements were performed in a conventional threeelectrode cell setup, using a rotating disk-electrode with deposited catalyst ink as a working electrode, $\mathrm{Hg} / \mathrm{Hg}_{2} \mathrm{SO}_{4}$ reference electrodes and a graphite rod counter electrode, in $\mathrm{H}_{2}$-saturated $1 \mathrm{~N} \mathrm{H}_{2} \mathrm{SO}_{4}$. The catalyst ink was prepared by adding $10 \mathrm{mg}$ MXene powder to $0.99 \mathrm{ml}$ absolute ethanol followed by the addition of $0.01 \mathrm{ml}$ of $c a .20 \%$ Nafion solution. This slurry was sonicated for $1 \mathrm{~h}$, and $20 \mu \mathrm{l}$ of the ink was drop cast on the polished $(0.03 \mu \mathrm{m})$ glassy carbon electrode $(0.196$ $\mathrm{cm}^{-2}$ surface area) resulting in a MXene loading of $1 \mathrm{mg} \mathrm{cm}$ geo ${ }^{-2}$. For the preparation of the electrodes with a MXene loading of $0.1 \mathrm{mg} \mathrm{cm}_{\text {geo }}{ }^{-2}, 10 \mathrm{mg}$ MXene powder, $4.95 \mathrm{ml}$ of absolute ethanol and $0.05 \mathrm{ml}$ of ca. $20 \%$ Nafion solution were mixed and $10 \mu \mathrm{l}$ of the ink was drop cast on the glassy carbon electrode. $\mathrm{The} \mathrm{Hg} / \mathrm{Hg}_{2} \mathrm{SO}_{4}$ reference electrode was calibrated versus $\mathrm{RHE}$ in the same electrolyte saturated with $\mathrm{H}_{2}$, after HER measurements, by either measuring the voltage, $\mathrm{E}_{\text {offset, }}$ corresponding to zero current (from $\mathrm{CV}$ scan at $1 \mathrm{mV} \mathrm{s}^{-1}$ ) from hydrogen oxidation/evolution on a platinum electrode or measuring the open circuit voltage. This voltage value was defined as $0 \mathrm{~V}$ vs. RHE (which corresponds to $-0.704 \mathrm{~V}$ vs. $\mathrm{Hg} / \mathrm{Hg}_{2} \mathrm{SO}_{4}$ in $1 \mathrm{~N} \mathrm{H}_{2} \mathrm{SO}_{4}$ ). Note that measurements of HER currents should be performed under the same conditions $(\mathrm{pH}$, $\mathrm{P}_{\mathrm{H} 2}$ ) for which the reference potential was established, i.e. $\mathrm{H}_{2}$ saturation. Indeed, HER measurements under Ar saturation may result in apparent decrease of the overpotential, however this artifact can merely be due to the dependence of $\mathrm{E}_{\mathrm{H} 2 / \mathrm{H}^{+}}$on $\mathrm{H}_{2}$ partial pressure, according to Nernst equation (eq. 1), which will not be accounted for by converting $E_{\text {measured }}$ to $E_{\text {RHE }}$ via a simple addition of $E_{\text {offset }}$ term, determined during calibration as a voltage corresponding to zero current from hydrogen oxidation/evolution on a platinum electrode ${ }^{5}$ (see above):

$\mathrm{E}_{\mathrm{H} 2 / \mathrm{H}^{+}}=\mathrm{E}_{\mathrm{H} 2 / \mathrm{H}^{+}}{ }^{0}+\mathrm{RT} / \mathrm{nF} \cdot \ln \left(\mathrm{a}_{\mathrm{H}+} / \mathrm{P}_{\mathrm{H} 2}\right)$ 
where $\mathrm{E}_{\mathrm{H} 2 / \mathrm{H}^{+}}{ }^{0}-\mathrm{H}_{2} / \mathrm{H}^{+}$is equilibrium potential, $0 \mathrm{~V}$ vs. $\mathrm{NHE}\left(\mathrm{pH} 0,1 \mathrm{~atm} \mathrm{H}_{2}\right.$ pressure), a $\mathrm{H}^{+}-\mathrm{H}^{+}$ activity in solution, $\mathrm{P}_{\mathrm{H} 2}$-partial pressure of $\mathrm{H}_{2}$ in solution

Correction for ohmic losses (iR correction) was done by subtracting the ohmic voltage drop from the measured potential, using the resistance value determined by impedance measurements. Steady-state galvanostatic measurements of the HER activity were performed by applying incrementally increased negative currents, and the potentials corresponding to the plateau of the E-t curves were used for plotting Tafel dependencies.

The electrochemically active surface area (ECSA) of the electrodes was estimated via the measurements of the electrode area-normalized double layer capacitance $\left(\mathrm{C}_{\mathrm{dl}}\right)$ by recording the scan rate-dependence of the non-Faradaic capacitive current that is associated with double-layer charging, as demonstrated for a representative electrode in Figure $\mathrm{S} 11$. The average $\mathrm{C}_{\mathrm{dl}}$ values (5.4 mF cm${ }^{-2}$ for $\mathrm{Mo}_{2} \mathrm{CT}_{x}$ : $\mathrm{Co}$ and $1.8 \mathrm{mF} \mathrm{cm}^{-2}$ for $\mathrm{Mo}_{2} \mathrm{C}_{x}$ ) were converted to ECSA using the equation $\mathrm{ECSA}=\mathrm{C}_{\mathrm{dl}} * \mathrm{~S} / \mathrm{C}_{\mathrm{s}}$, where $\mathrm{S}$ is the geometric surface area of the electrode, $\mathrm{C}_{\mathrm{s}}$ is the specific capacity of a flat metal surface $(0.04 \mathrm{mF} \mathrm{cm})^{-2}$ resulting in ECSA values of $26.7 \mathrm{~cm}^{2}$ for

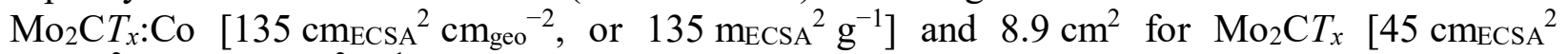
$\mathrm{cm}_{\text {geo }}{ }^{-2}$, or $45 \mathrm{mECSA}^{2} \mathrm{~g}^{-1}$ ]. These values were used to normalize the currents.

DFT calculations. All structural relaxation calculations were performed using a plane-wave basis set as implemented in the VASP package until the residual forces acting on atoms were less than $0.03 \mathrm{eV} / \AA{ }^{7,8}$ We employed the Projector Augmented Wave (PAW) method to describe the core electrons ${ }^{9}$ and the Perdew Burke Ernzerhof exchange-correlation (XC) functional. ${ }^{10}$ The kinetic energy cutoff for the wave function and charge density was set to $450 \mathrm{eV}$, and a gammapoint k-grid was used for the $4 \times 4 \times 1$ unit cell calculations. A vacuum region greater than $12 \AA$ was used in the direction normal to the sheets to avoid interaction between neighboring images.

The differential hydrogen adsorption energy, $\Delta E_{\mathrm{H}}$, was calculated as:

$\Delta E_{\mathrm{H}}=E_{\text {system }+n \mathrm{H}}-E_{\text {system }+(n-1) \mathrm{H}}-1 / 2 E_{\mathrm{H}_{2}}$

where, $E_{\text {system }+n \mathrm{H}}$ is the total energy of the $\mathrm{Mo}_{2} \mathrm{CO}_{2}$ or the Co-substituted $\mathrm{Mo}_{2} \mathrm{CO}_{2}$ system with $n$ adsorbed hydrogen atoms, $E_{\text {system }+(n-1) \mathrm{H}}$ is the total energy of the same system with $(n-1)$ adsorbed hydrogen atoms and $E_{\mathrm{H}_{2}}$ is the energy of a hydrogen molecule in the gas phase. The free energy of hydrogen adsorption was then calculated as $\Delta G_{\mathrm{H}}=\Delta E_{\mathrm{H}}+0.37 \mathrm{eV}$, where $\Delta E_{\mathrm{H}}$ is the differential hydrogen adsorption energy as computed above, and the value of $0.37 \mathrm{eV}$, which is taken from ref. ${ }^{11}$ includes changes in the zero-point energy and the entropy between the adsorbed state and the gas phase of hydrogen. 
(a)

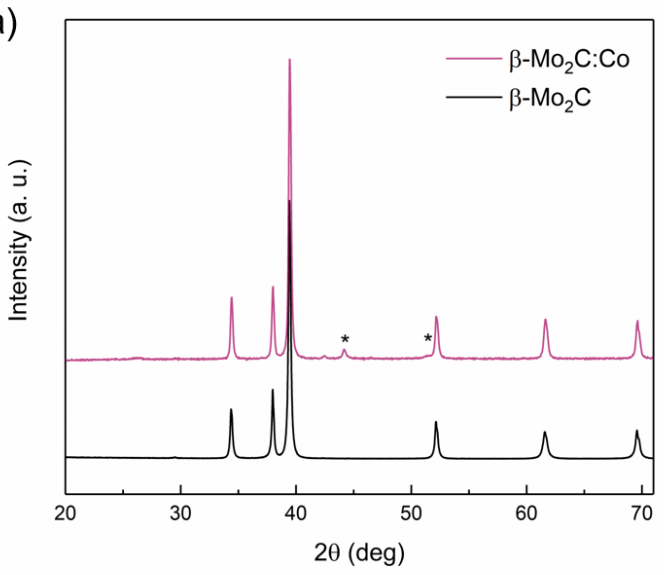

(b)

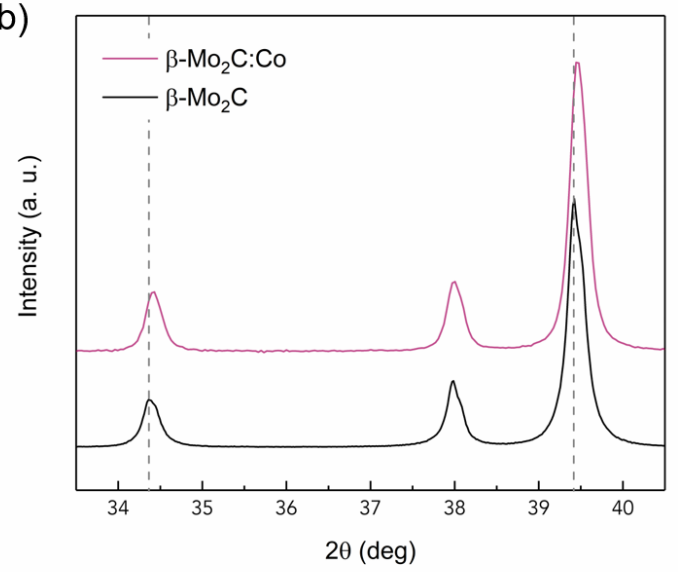

Figure S1. (a) XRD patterns of as-synthesized $\beta-\mathrm{Mo}_{2} \mathrm{C}$ : Co and commercial $\beta-\mathrm{Mo}_{2} \mathrm{C}$ (peaks due to metallic Co impurity are labelled by asterisks), and (b) magnified 34-40 ${ }^{\circ}$ region highlighting (100) and (101) peak shifts towards higher diffraction angles upon Co doping.

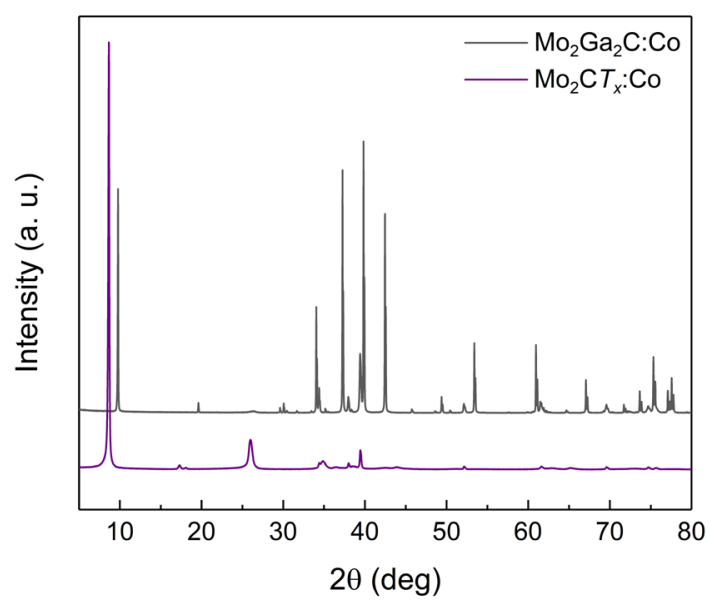

Figure S2. XRD patterns for $\mathrm{Mo}_{2} \mathrm{Ga}_{2} \mathrm{C}: \mathrm{Co}$ and $\mathrm{Mo}_{2} \mathrm{C} T_{x}$ : $\mathrm{Co}$. 


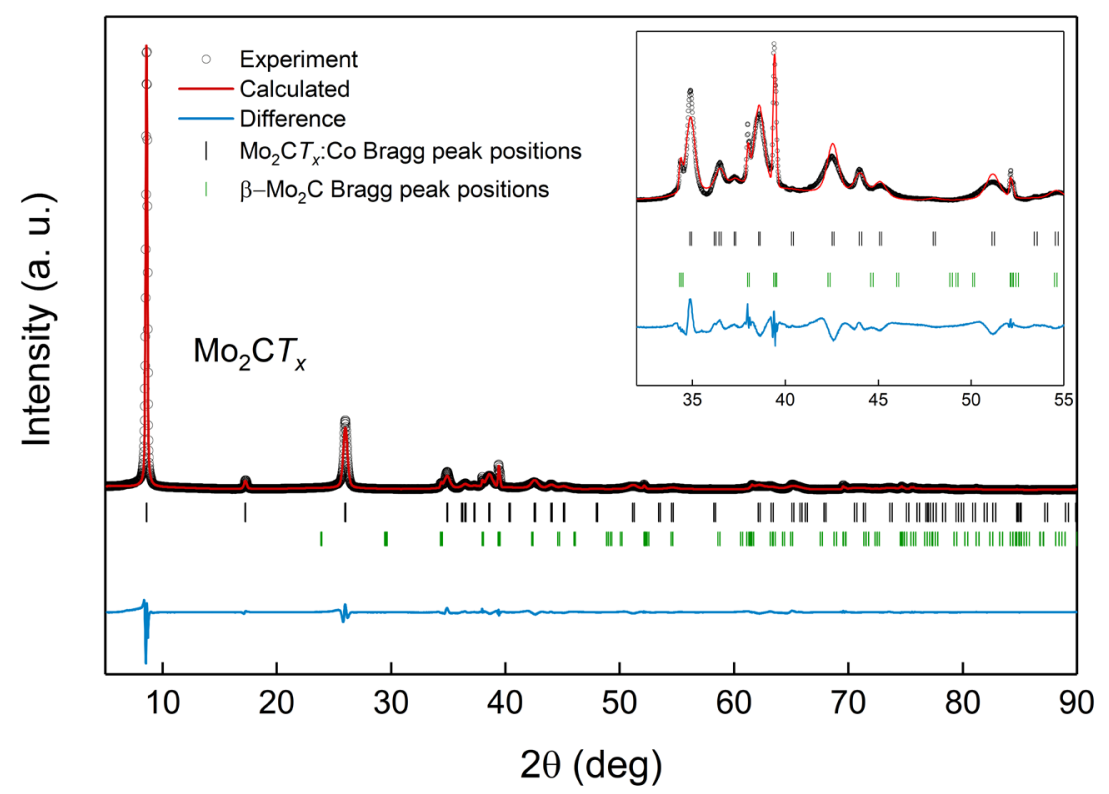

Figure S3. Le Bail fit for $\mathrm{Mo}_{2} \mathrm{C} T_{x}$ material revealing that all reflections could be assigned to $\mathrm{Mo}_{2} \mathrm{C} T_{x}$ and $\beta-\mathrm{Mo}_{2} \mathrm{C}$ phases.
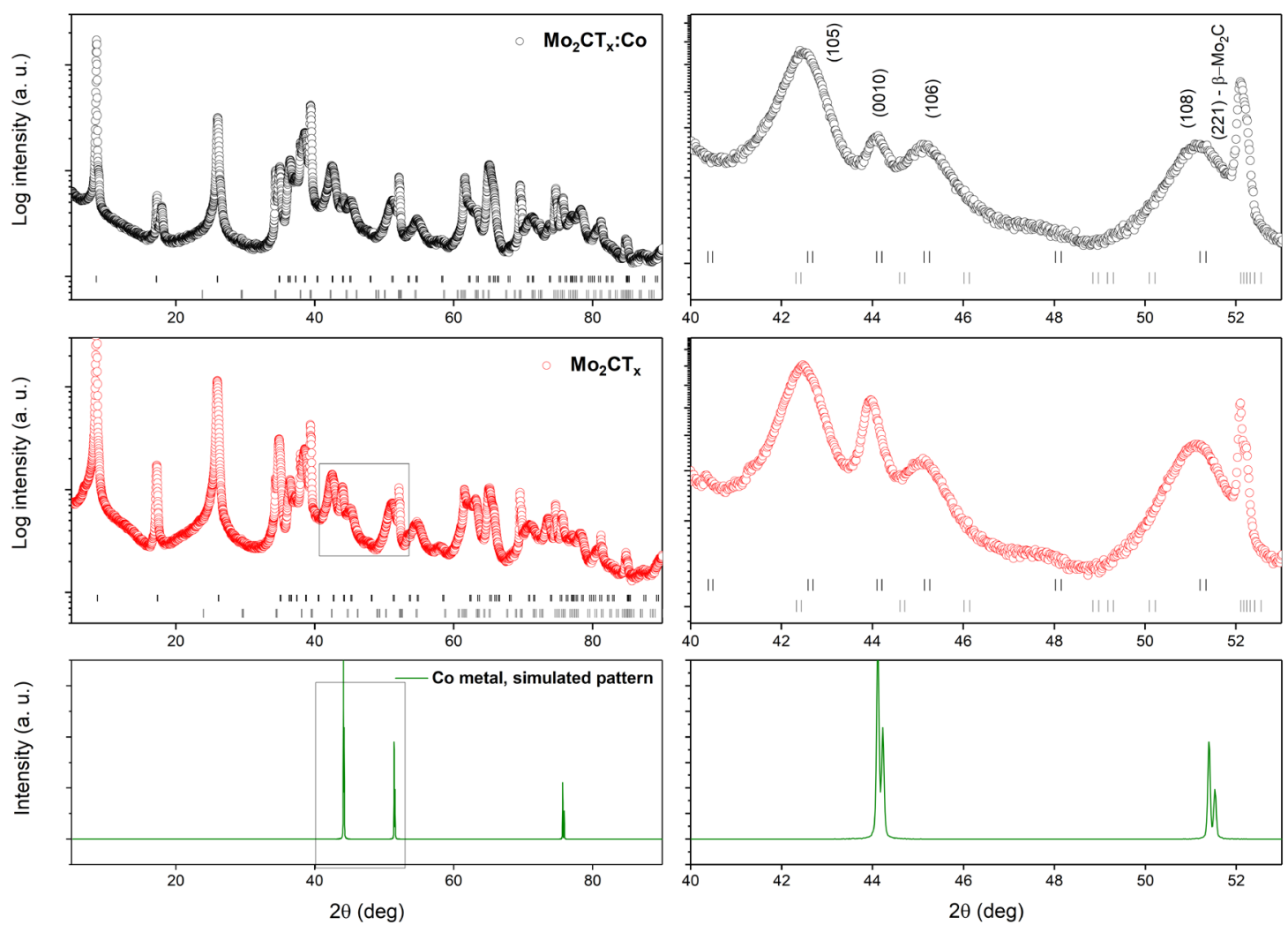

Figure S4. Experimental XRD patterns for $\mathrm{Mo}_{2} \mathrm{C} T_{x}: \mathrm{Co}, \mathrm{Mo}_{2} \mathrm{C} T_{x}$ (log intensity coordinates) revealing an identical set of peaks for both MXene materials. All peaks are indexed as $P 6_{3} / m m c$ space group, Miller indices are shown for the $\mathrm{Mo}_{2} \mathrm{C} T_{x}$ :Co phase. Only the peak at $\sim 52^{\circ}$ belongs to $\beta-\mathrm{Mo}_{2} \mathrm{C}$. Simulated XRD pattern of metallic Co is shown for comparison, demonstrating that no peaks attributed to metallic Co can be found on the XRD pattern of $\mathrm{Mo}_{2} \mathrm{CT}_{x}$ : Co. 
Table S1. Extracted intensities for $\mathrm{Mo}_{2} \mathrm{C} T_{x}$ : Co from Le Bail fitting of the experimental data.

\begin{tabular}{|c|c|c|c|c|c|c|c|c|}
\hline No. & $\mathbf{h}$ & $\mathbf{k}$ & 1 & Multiplicity & $2 \theta$ (deg) & $\mathbf{I}_{\text {calc }}$ & $I_{\text {obs }}$ & d-hkl \\
\hline 1 & 0 & 0 & 2 & 2 & 8.591 & 106176.1 & 106176.4 & 10.28371 \\
\hline 2 & 0 & 0 & 4 & 2 & 17.232 & 3210.2 & 3210.2 & 5.141857 \\
\hline 3 & 0 & 0 & 6 & 2 & 25.972 & 35779 & 35779.1 & 3.427904 \\
\hline 4 & 0 & 0 & 8 & 2 & 34.869 & 9766.2 & 9766.1 & 2.570928 \\
\hline 5 & 1 & 0 & 0 & 6 & 36.176 & 0 & 0 & 2.480994 \\
\hline 6 & 1 & 0 & 1 & 12 & 36.448 & 2764.1 & 2763.9 & 2.463138 \\
\hline 7 & 1 & 0 & 2 & 12 & 37.252 & 1027 & 1027.1 & 2.411799 \\
\hline 8 & 1 & 0 & 3 & 12 & 38.56 & 11621.7 & 11621.5 & 2.332933 \\
\hline 9 & 1 & 0 & 4 & 12 & 40.331 & 104.1 & 104.1 & 2.234481 \\
\hline 10 & 1 & 0 & 5 & 12 & 42.517 & 7669.8 & 7669.7 & 2.124489 \\
\hline 11 & 0 & 0 & 10 & 2 & 43.99 & 3479.7 & 3479.8 & 2.056742 \\
\hline 12 & 1 & 0 & 6 & 12 & 45.072 & 2499.3 & 2499.2 & 2.009818 \\
\hline 13 & 1 & 0 & 7 & 12 & 47.953 & 353 & 353 & 1.895603 \\
\hline 14 & 1 & 0 & 8 & 12 & 51.122 & 4762.8 & 4762.9 & 1.785275 \\
\hline 15 & 0 & 0 & 12 & 2 & 53.414 & 127.6 & 127.6 & 1.713952 \\
\hline 16 & 1 & 0 & 9 & 12 & 54.551 & 1802.2 & 1802.2 & 1.68087 \\
\hline 17 & 1 & 0 & 10 & 12 & 58.219 & 278.6 & 278.5 & 1.583403 \\
\hline 18 & 1 & 0 & 11 & 12 & 62.111 & 6203.9 & 6204.4 & 1.493203 \\
\hline 19 & 0 & 0 & 14 & 2 & 63.246 & 3050.8 & 3050.8 & 1.469102 \\
\hline 20 & 1 & 1 & 0 & 6 & 65.063 & 4826.5 & 4824.3 & 1.432403 \\
\hline 21 & 1 & 1 & 2 & 12 & 65.77 & 1545.4 & 1547.8 & 1.418706 \\
\hline 22 & 1 & 0 & 12 & 12 & 66.219 & 0.2 & 0.2 & 1.410171 \\
\hline 23 & 1 & 1 & 4 & 12 & 67.868 & 101.5 & 101.5 & 1.379861 \\
\hline 24 & 1 & 0 & 13 & 12 & 70.543 & 1988.2 & 1988.6 & 1.333962 \\
\hline 25 & 1 & 1 & 6 & 12 & 71.299 & 1205.9 & 1205.9 & 1.321655 \\
\hline 26 & 0 & 0 & 16 & 2 & 73.63 & 2288.4 & 2288.5 & 1.285464 \\
\hline 27 & 1 & 0 & 14 & 12 & 75.086 & 424.8 & 425 & 1.264105 \\
\hline 28 & 1 & 1 & 8 & 12 & 75.991 & 1088.9 & 1090.4 & 1.251295 \\
\hline 29 & 2 & 0 & 0 & 6 & 76.772 & 265.4 & 264.3 & 1.240497 \\
\hline 30 & 2 & 0 & 1 & 12 & 76.937 & 320.2 & 319.7 & 1.238247 \\
\hline 31 & 2 & 0 & 2 & 12 & 77.432 & 448.3 & 449.1 & 1.231569 \\
\hline 32 & 2 & 0 & 3 & 12 & 78.254 & 1360.6 & 1360.6 & 1.220676 \\
\hline 33 & 2 & 0 & 4 & 12 & 79.401 & 0 & 0 & 1.205899 \\
\hline
\end{tabular}




\begin{tabular}{|l|l|l|l|l|l|l|l|l|}
\hline 34 & 1 & 0 & 15 & 12 & 79.863 & 0 & 0 & 1.20008 \\
35 & 2 & 0 & 5 & 12 & 80.869 & 798.2 & 798.3 & 1.187667 \\
36 & 1 & 1 & 10 & 12 & 81.889 & 0 & 0 & 1.175431 \\
37 & 2 & 0 & 6 & 12 & 82.656 & 0 & 0 & 1.166467 \\
38 & 2 & 0 & 7 & 12 & 84.758 & 22.7 & 22.4 & 1.142818 \\
39 & 0 & 0 & 18 & 2 & 84.775 & 26.8 & 26.6 & 1.142635 \\
40 & 1 & 0 & 16 & 12 & 84.892 & 84.8 & 85.7 & 1.14136 \\
41 & 2 & 0 & 8 & 12 & 87.175 & 678.9 & 678.9 & 1.117241 \\
42 & 1 & 1 & 12 & 12 & 88.989 & 236 & 236.1 & 1.099105 \\
43 & 2 & 0 & 9 & 12 & 89.909 & 687.2 & 686.7 & 1.090231 \\
\hline
\end{tabular}



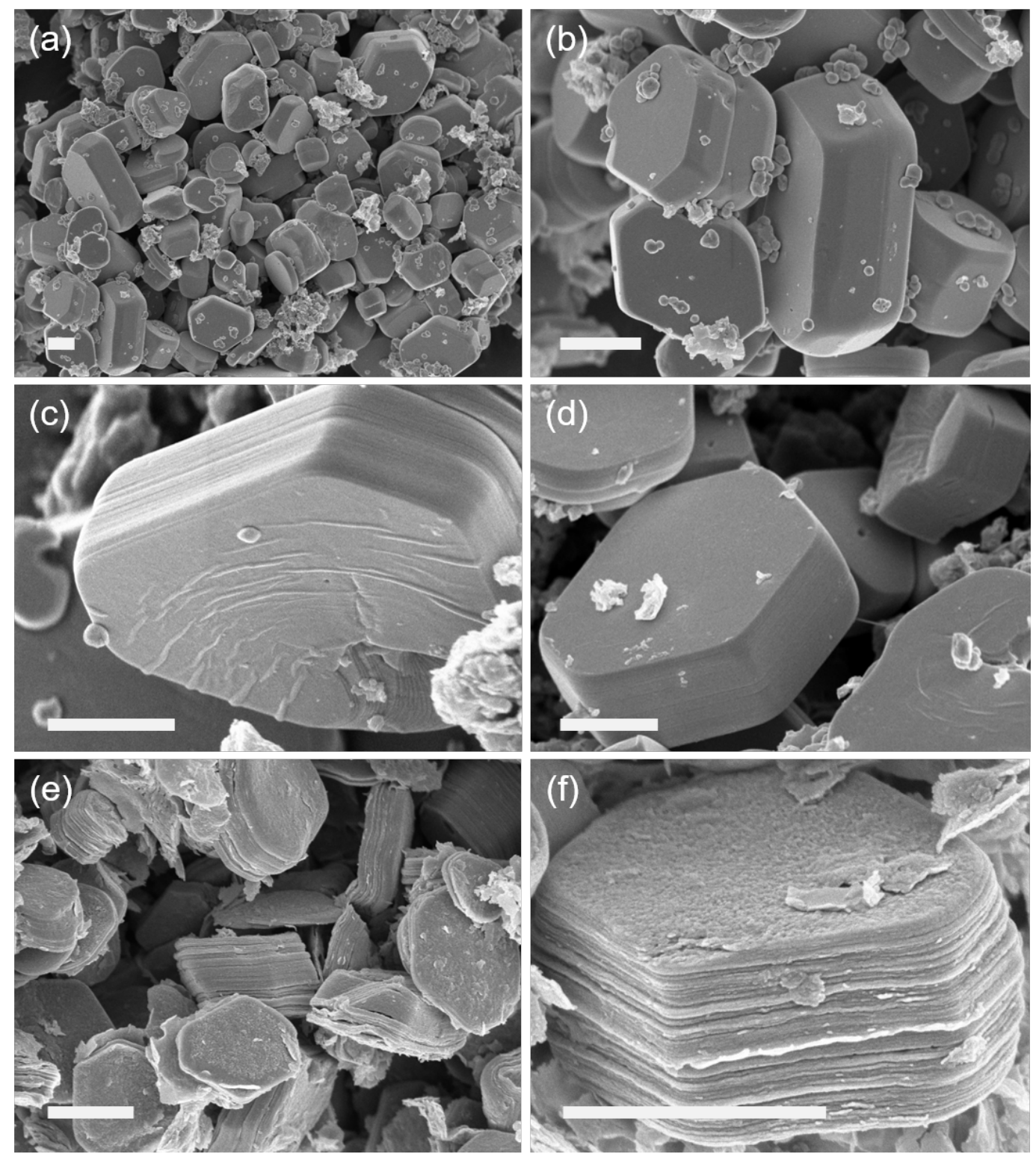

Figure S5. SEM images of $\mathrm{Mo}_{2} \mathrm{Ga}_{2} \mathrm{C}: \mathrm{Co}(\mathrm{a}, \mathrm{b})$ and $\mathrm{Mo}_{2} \mathrm{C} T_{x}$ :Co before (c, d) and after (e, f) intercalation of TBAOH and sonication. Scale bar is $1 \mu \mathrm{m}$. 

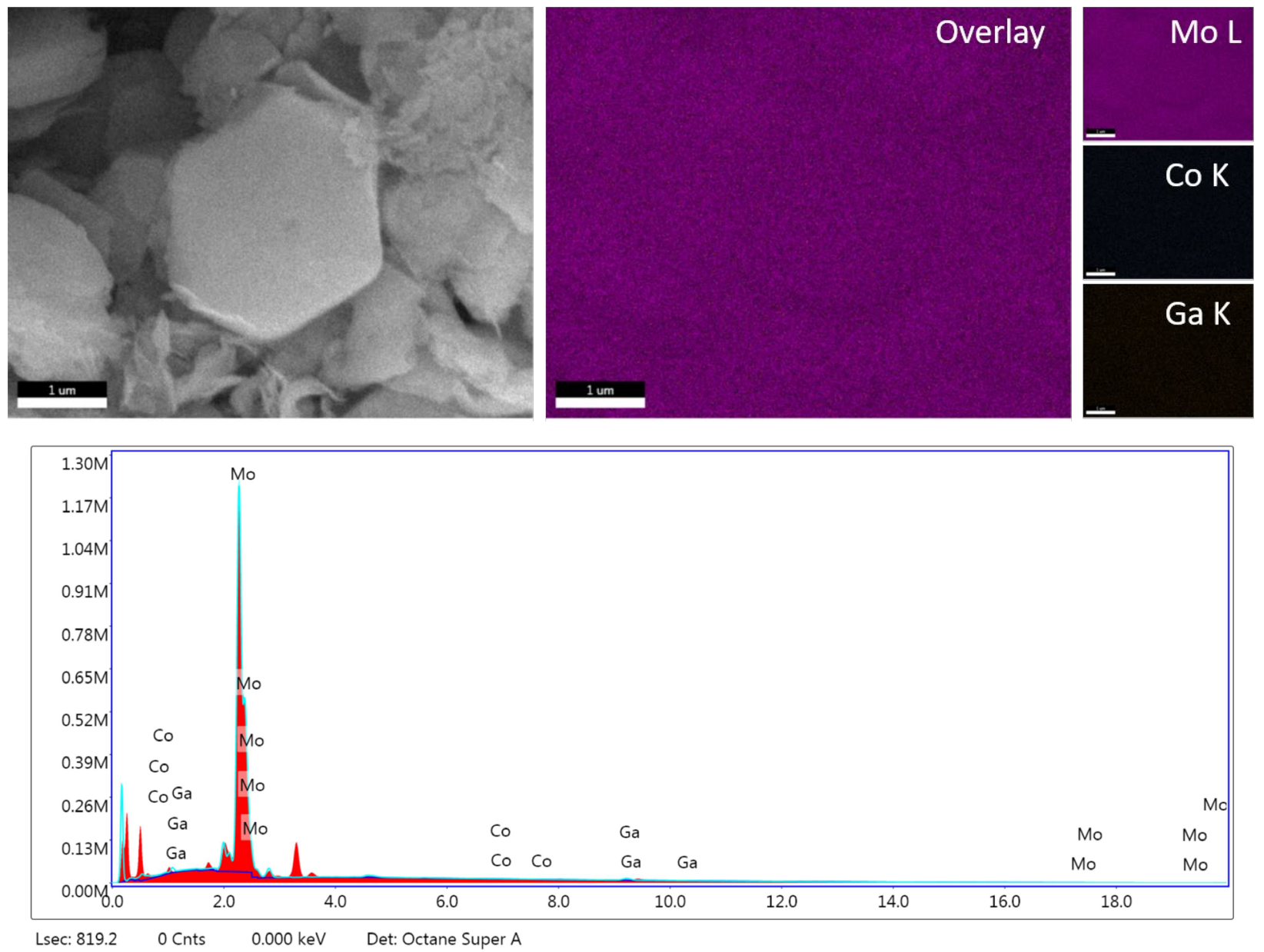

$\begin{array}{lllllllll}\text { Element } & \text { Weight } \% & \text { Atomic \% } & \text { Net Int. } & \text { Error \% } & \text { Kratio } & Z & \text { A } & F\end{array}$

\begin{tabular}{cccccccccc} 
MoL & 97.80 & 96.97 & 27077.30 & 1.16 & 0.9673 & 0.9990 & 0.9901 & 1.0000 \\
\hline CoK & 0.09 & 0.15 & 16.90 & 30.28 & 0.0010 & 1.1080 & 0.9315 & 1.0517 \\
\hline GaK & 2.11 & 2.88 & 221.60 & 4.25 & 0.0246 & 1.0646 & 0.9752 & 1.1228
\end{tabular}

Figure S6. Results of the EDX mapping for the representative area of $\mathrm{Mo}_{2} \mathrm{CT}_{x}$ :Co sample. Carbon, oxygen, fluorine are not included, only metallic elements are shown. Data demonstrate that Co content is too low to be reliably quantified by EDX. 


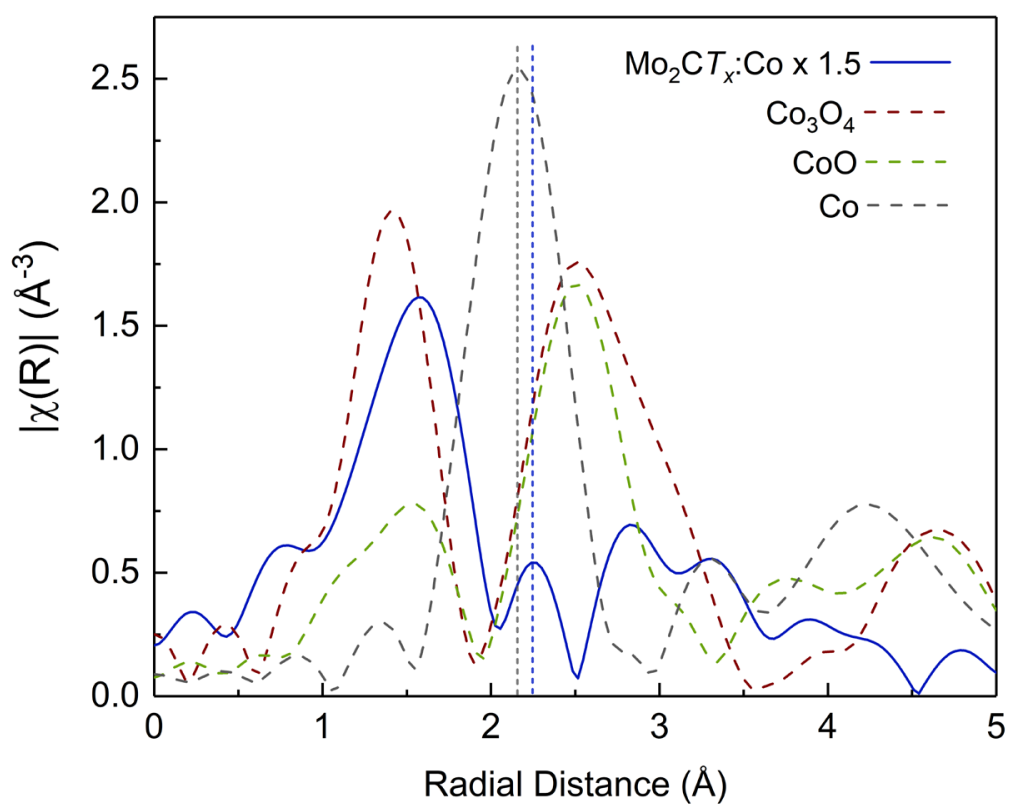

Figure S7. Comparison of the phase-uncorrected Fourier-transform of the Co K-edge EXAFS spectra of $\mathrm{Mo}_{2} \mathrm{C} T_{x}$ :Co and $\mathrm{Co}, \mathrm{CoO}, \mathrm{Co}_{3} \mathrm{O}_{4}$ reference materials.

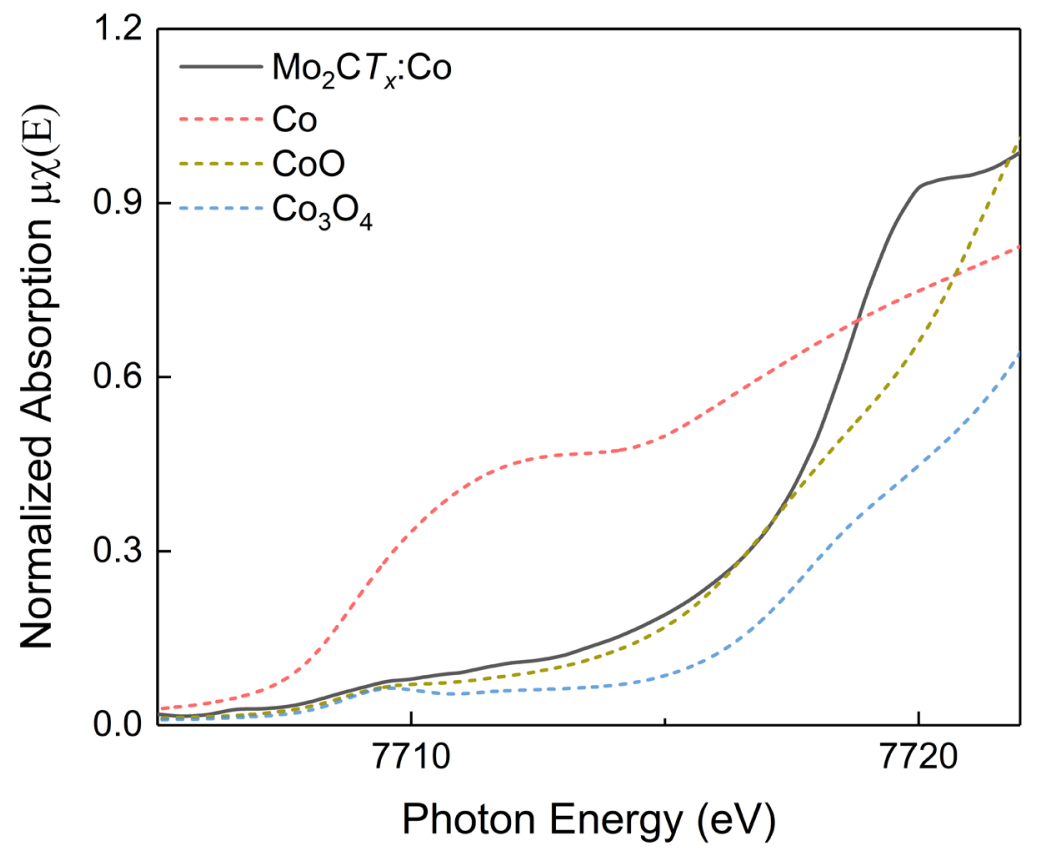

Figure S8. Comparison of the pre-edge regions of the normalized Co K-edge XANES spectra for $\mathrm{Mo}_{2} \mathrm{C} T_{x}: \mathrm{Co}$ and $\mathrm{Co}$, $\mathrm{CoO}, \mathrm{Co}_{3} \mathrm{O}_{4}$ reference materials. 


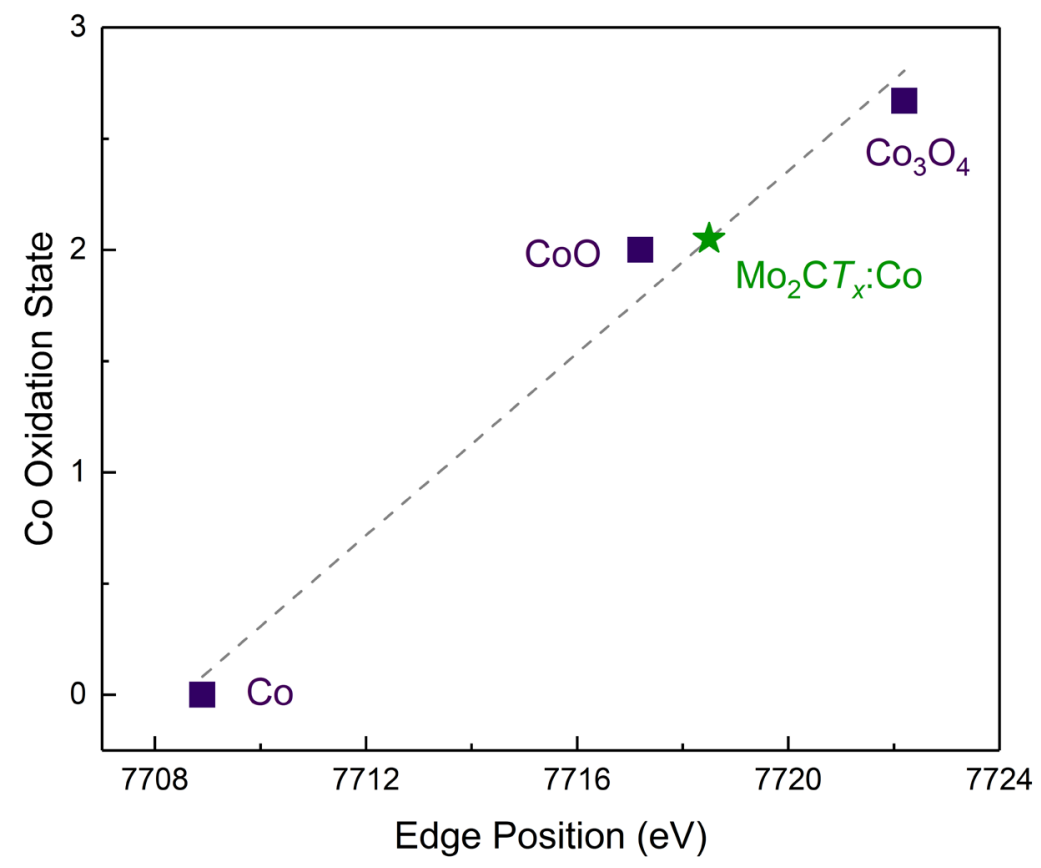

Figure S9. Estimation of the cobalt oxidation state in $\mathrm{Mo}_{2} \mathrm{C}_{x}$ : $\mathrm{Co}$ from the edge position in the XANES spectra of references $\mathrm{Co}, \mathrm{CoO}, \mathrm{Co}_{3} \mathrm{O}_{4}$.

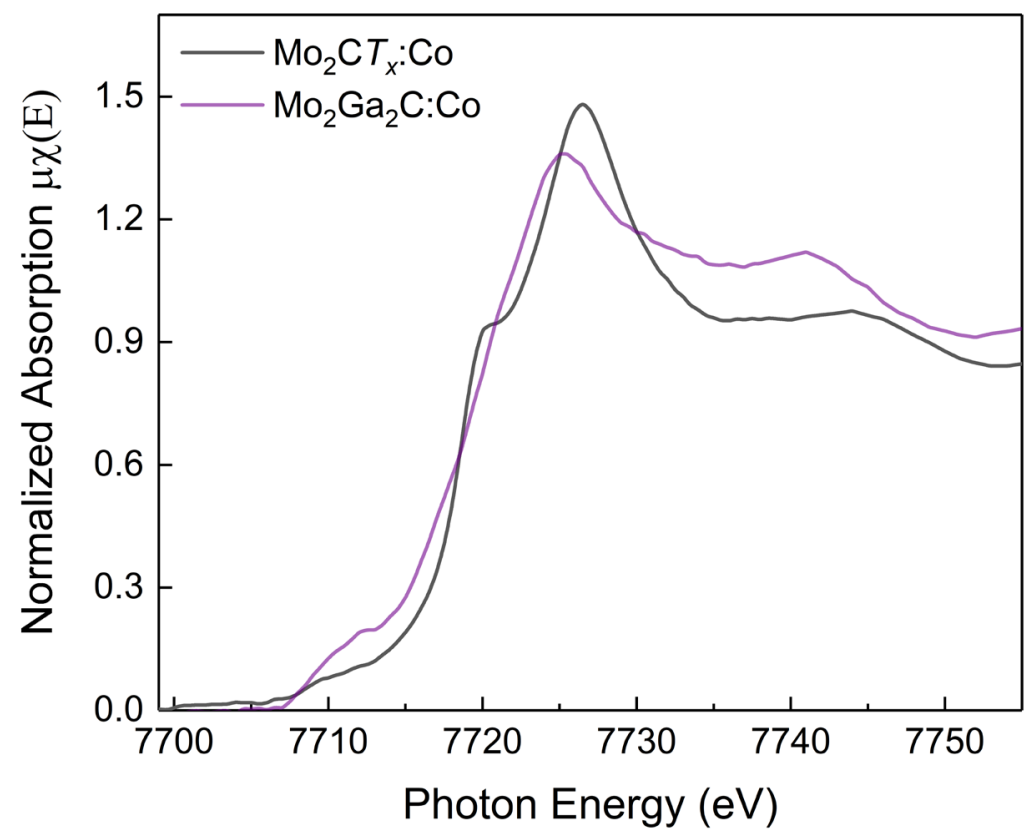

Figure S10. Comparison of the Co K-edge XANES spectra of $\mathrm{Mo}_{2} \mathrm{CT}_{x}$ : $\mathrm{Co}$ and $\mathrm{Mo}_{2} \mathrm{Ga}_{2} \mathrm{C}$ :Co materials. 


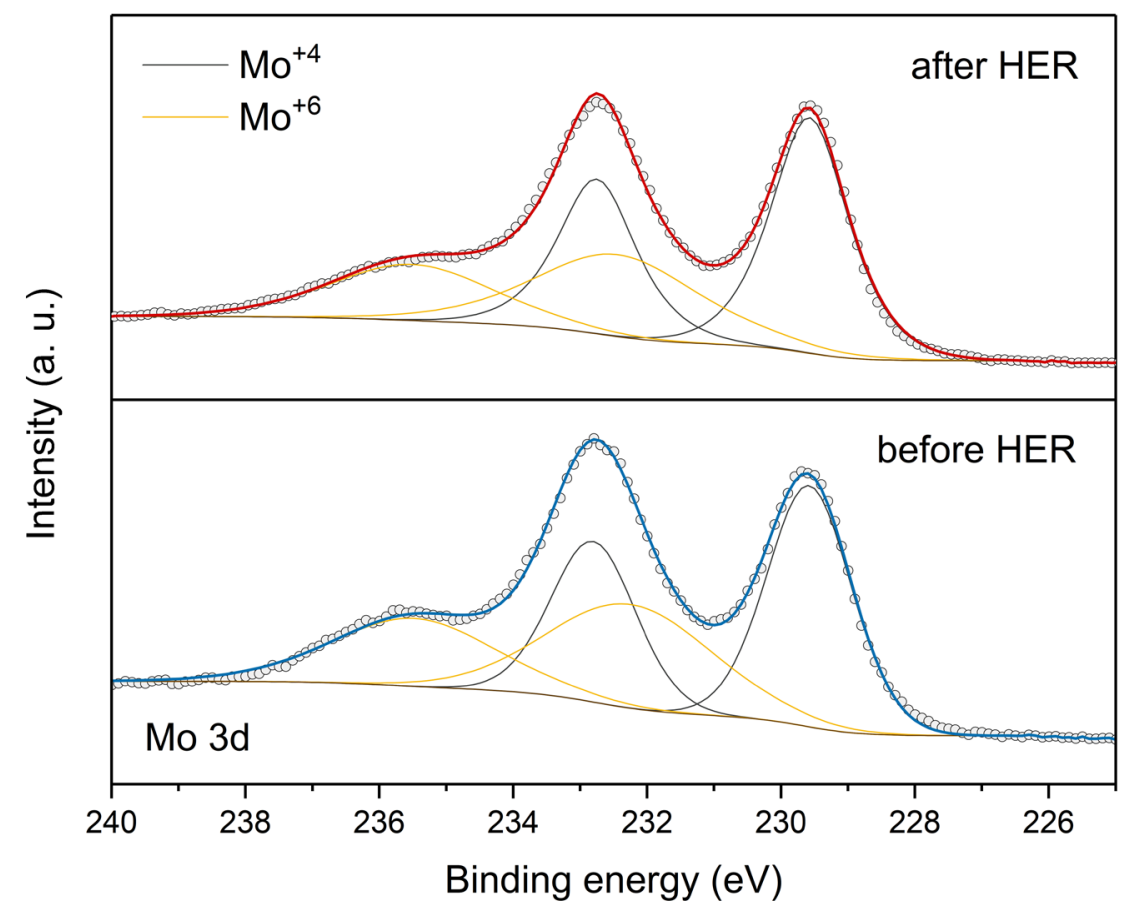

Figure S11. Core-level Mo 3d spectra of $\mathrm{Mo}_{2} \mathrm{C} T_{x}$ :Co before and after HER measurements.

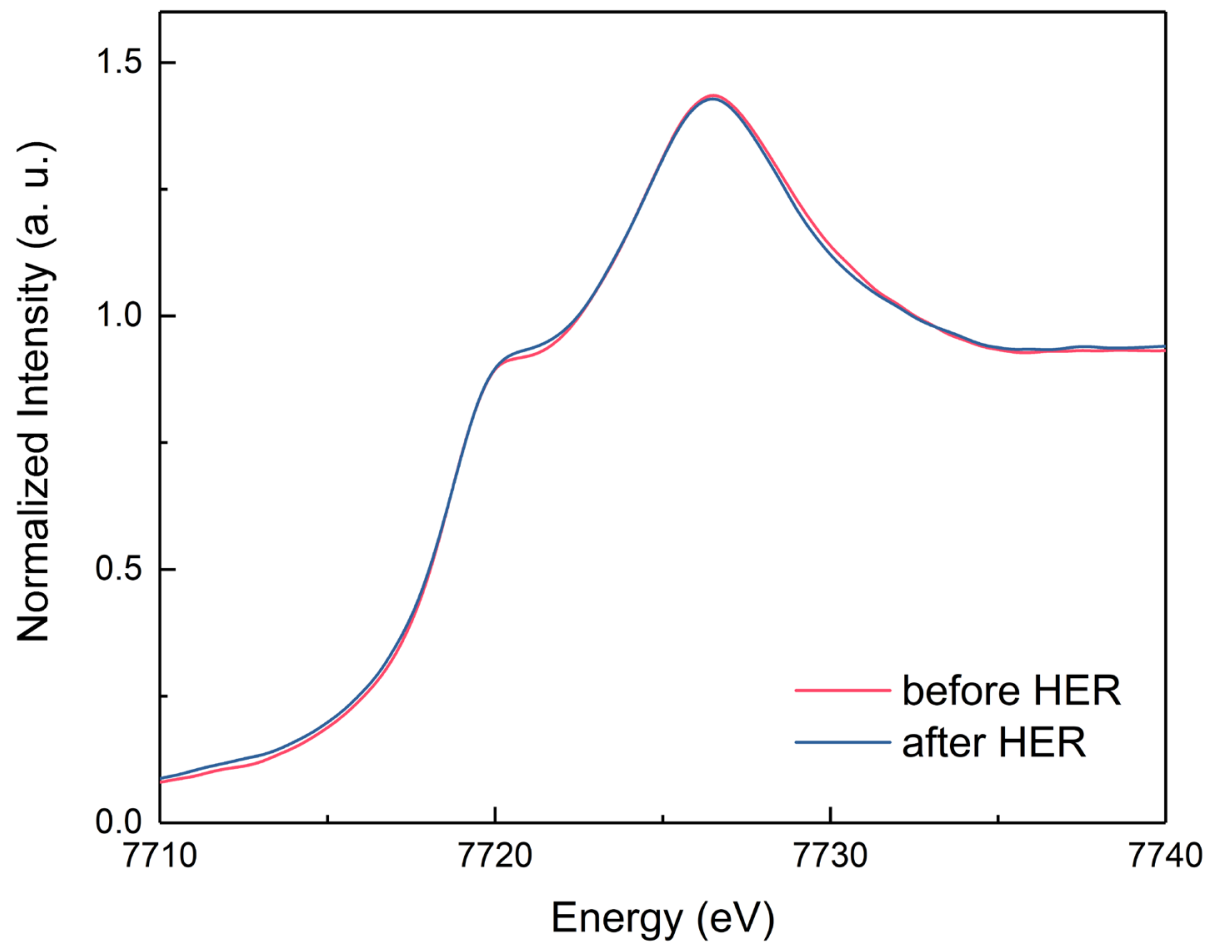

Figure S12. Comparison of the normalized Co K-edge XANES spectra of $\mathrm{Mo}_{2} \mathrm{C} T_{x}$ :Co before and after HER measurements. 

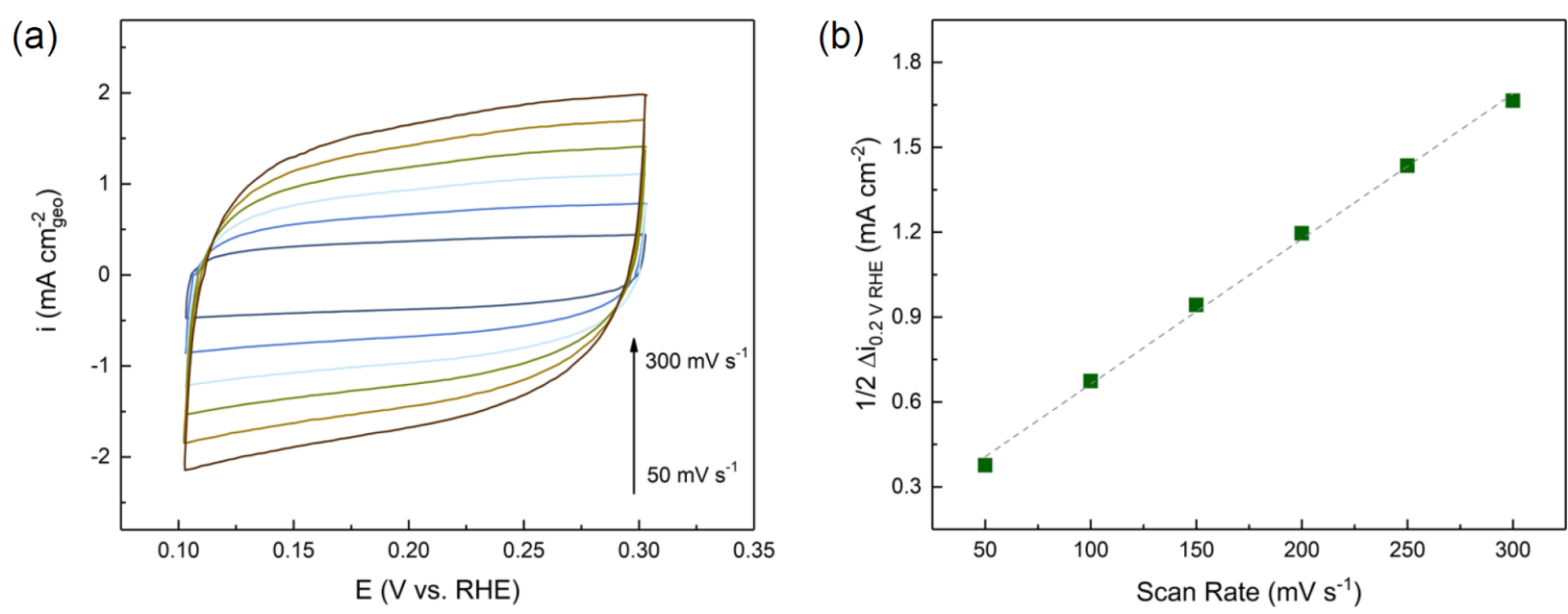

Figure S13. (a) $\mathrm{CV}$ scans recorded in the non-Faradaic region for a representative $\mathrm{Mo}_{2} \mathrm{C} T_{x}$ :Co-based electrode using scan rates of 50,100,150,200, 250, $300 \mathrm{mV} \mathrm{s}^{-1}$ in $1 \mathrm{~N} \mathrm{H}_{2} \mathrm{SO}_{4}$ electrolyte. (b) Scan rate dependence of the current density of a $\mathrm{Mo}_{2} \mathrm{CT}_{x}$ :Co-based electrode from panel (a) used to determine the area normalized double layer capacity $\left(\mathrm{C}_{\mathrm{dl}}\right)$ corresponding to the slope of the linear fit shown with a dashed line. The calculated $\mathrm{C}_{\mathrm{dl}}$ value for a given electrode is $5.1 \mathrm{mF} \mathrm{cm}$, average capacity value of $\mathrm{Mo}_{2} \mathrm{C} T_{x}$ :Co-based electrodes used to generate Tafel plots presented in the main text is $5.4 \mathrm{mF} \mathrm{cm}^{-2}$.

To estimate the intrinsic activity of the catalysts, we calculated the average turnover frequency (TOF), using equation 3:

$$
\mathrm{TOF}=\frac{\mathrm{n}\left(\mathrm{H}_{2}\right)}{\mathrm{N}(\mathrm{O})}
$$

where TOF - turnover frequency $\left(\mathrm{H}_{2} \mathrm{~s}^{-1}\right)$

$n\left(\mathrm{H}_{2}\right)$ - amount of $\mathrm{H}_{2}$ produced per unit of electrode area per second $\left(\mathrm{mol} \mathrm{H}_{2} \mathrm{~cm}^{-2} \mathrm{~s}^{-1}\right)$

$\mathrm{N}(\mathrm{O})$ - number of $\mathrm{O}$ sites (active sites) per unit of electrode area $\left(\mathrm{mol} \mathrm{cm}^{-2}\right)$

Here, we assume that all accessible $\mathrm{O}$ sites are catalytically active, that gives a conservative estimation of the number active sites (lower boundary).

Amount of $\mathrm{H}_{2}$ produced per unit of electrode area per second $\left(\mathrm{n}\left(\mathrm{H}_{2}\right), \mathrm{mol} \mathrm{H}_{2} \mathrm{~cm}^{-2} \mathrm{~s}^{-1}\right)$ :

$\mathrm{n}\left(\mathrm{H}_{2}\right)=\frac{|\mathrm{j}|}{2 \mathrm{~F}}$

where $\mathrm{j}$ is the current density $\left(\mathrm{A} \mathrm{cm}^{-2}\right)$ and $\mathrm{F}$ is the Faraday constant $\left(96485 \mathrm{C} \mathrm{mol}^{-1}\right)$. Coefficient $1 / 2$ accounts for 2 electrons required to reduce protons to form a $\mathrm{H}_{2}$ molecule.

$\mathrm{n}\left(\mathrm{H}_{2}\right)=\mathrm{j}\left[\mathrm{A} \mathrm{cm}^{-2}\right] \cdot 5.182 \cdot 10^{-6} \mathrm{~mol} \mathrm{C}^{-1}=\mathrm{j}\left[\mathrm{mA} \mathrm{cm}^{-2}\right] \cdot 5.182 \cdot 10^{-9} \mathrm{~mol} \mathrm{C}^{-1}$

Number of active sites (O atoms) per electrode surface area $\left(\mathrm{mol} \mathrm{cm}^{-2}\right)$

$$
\mathrm{N}(0)=\frac{\mathrm{S}_{\mathrm{ECSA}}}{\mathrm{S}(0) \cdot \mathrm{S}_{\mathrm{el}}} \cdot \frac{1}{\mathrm{~N}_{\mathrm{A}}}
$$

where $\mathrm{S}_{\mathrm{ECSA}}$ is the experimentally-determined, electrochemically active surface area $\left(\mathrm{cm}^{2}\right)$

$\mathrm{S}(\mathrm{O})$ is unit area containing one oxygen atom $\left(\mathrm{cm}^{2}\right)$ 
$\mathrm{S}_{\mathrm{el}}$ is the apparent electrode surface area $\left(0.196 \mathrm{~cm}^{2}\right)$

$\mathrm{N}_{\mathrm{A}}$ is the Avogadro constant $\left(6.022 \cdot 10^{23} \mathrm{~mol}^{-1}\right)$

To estimate the number of oxygen atoms (active sites) per unit of electrode area, we have calculated the area of $\mathrm{Mo}_{2} \mathrm{CO}_{2}$ containing one oxygen atom $\left(\mathrm{S}(\mathrm{O}), \mathrm{cm}^{2}\right)$, using geometric parameters from the DFT optimized model:

$\mathrm{S}(0)=\mathrm{r}^{2} \cdot \sin \alpha$

where $\mathrm{r}$ is the $\mathrm{O}-\mathrm{O}$ distance $\left(2.89 \AA=2.89 \cdot 10^{-8} \mathrm{~cm}\right)$

$\alpha-\angle \mathrm{O}-\mathrm{O}-\mathrm{O}\left(60^{\circ}\right.$, see Fig. S9)

$\mathrm{S}(\mathrm{O})=7.23 \AA^{2}=7.23 \cdot 10^{-16} \mathrm{~cm}^{2}$

$\mathrm{N}(\mathrm{O})=26.7 \mathrm{~cm}^{2} /\left(7.23 \cdot 10^{-16} \mathrm{~cm}^{2} * 0.196 \mathrm{~cm}^{2} * 6.022 \cdot 10^{23} \mathrm{~mol}^{-1}\right)=3.13 \cdot 10^{-7} \mathrm{~mol} \mathrm{~cm}^{-2}$

$\mathrm{TOF}=\mathrm{j}\left[\mathrm{mA} \mathrm{cm}^{-2}\right] \cdot 5.182 \cdot 10^{-9} \mathrm{~mol} \mathrm{C}^{-1} / 3.13 \cdot 10^{-7} \mathrm{~mol} \mathrm{~cm}^{-2}=\mathrm{j} * 1.656 \cdot 10^{-2} \mathrm{~s}^{-1}$

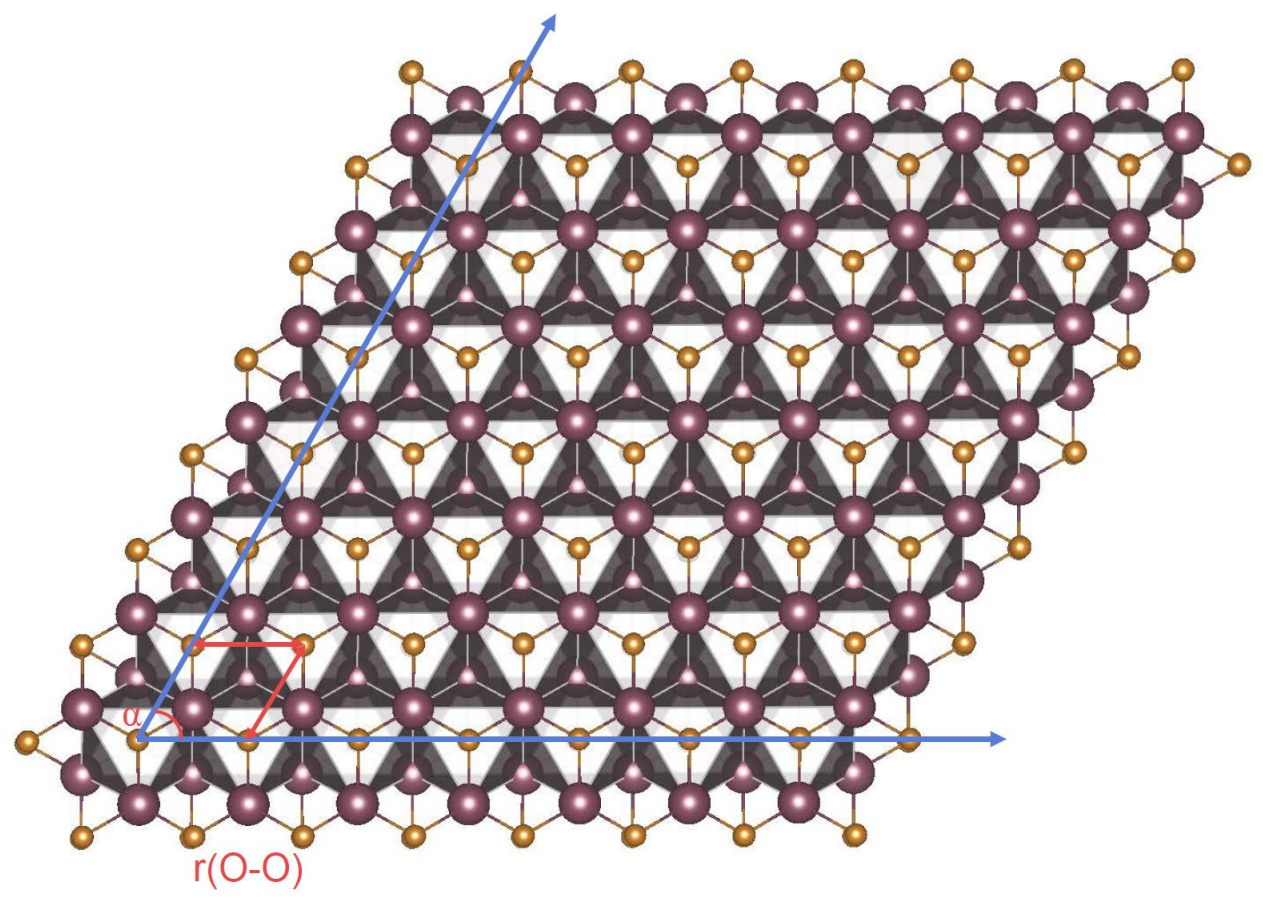

Figure S14. Model of $\mathrm{Mo}_{2} \mathrm{CT}_{x}$ structure demonstrating the estimation of the average area containing one oxygen atom. Geometry parameters were taken from DFT calculations and are: $\mathrm{r}(\mathrm{O}-\mathrm{O})=2.89 \AA, \alpha=60^{\circ}$. 


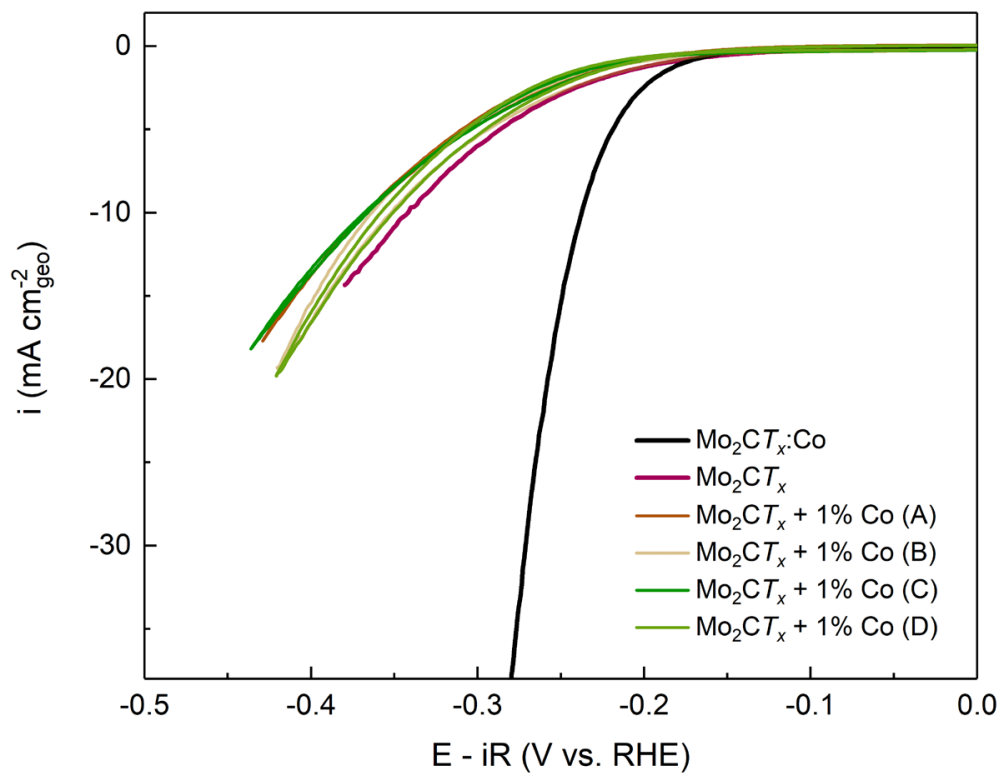

Figure S15. Polarization curves recorded for $\mathrm{Mo}_{2} \mathrm{C} T_{x}$ : $\mathrm{Co}, \mathrm{Mo}_{2} \mathrm{C} T_{x}$ and $\mathrm{Mo}_{2} \mathrm{C} T_{x}$ mixed with 1 wt. \% Co powder (325 mesh) with a scan rate of $10 \mathrm{mV} \mathrm{s}^{-1}$. All powders were deposited on glassy carbon electrodes with catalyst loading $0.1 \mathrm{mg} \mathrm{cm}^{-2}$ and measured in $1 \mathrm{~N} \mathrm{H}_{2} \mathrm{SO}_{4}$. Data for $\mathrm{Mo}_{2} \mathrm{C} T_{x}$ : $\mathrm{Co}$ and $\mathrm{Mo}_{2} \mathrm{C} T_{x}$ are the same as presented in the main text. For $\left(\mathrm{Mo}_{2} \mathrm{C} T_{x}+1 \% \mathrm{Co}\right)$ sample, four independent measurements are shown, highlighting no observable effect of the presence of metallic cobalt on HER activity.

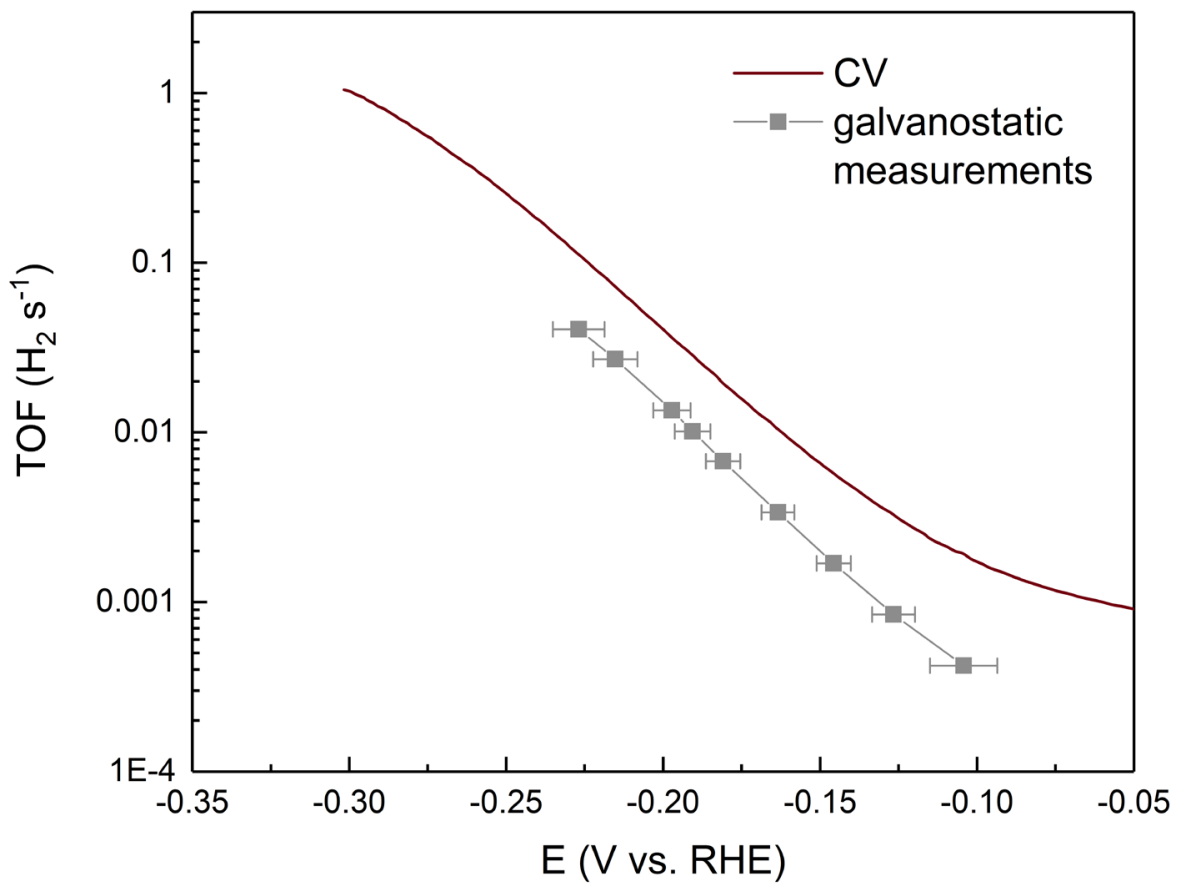

Figure S16. Turnover frequency (TOF) plot for $\mathrm{Mo}_{2} \mathrm{C}_{x}$ : $\mathrm{Co}\left(0.1 \mathrm{mg} \mathrm{cm}_{\text {geo }}{ }^{-2}\right.$ loading). $\mathrm{CV}$ measurements result in an overestimation of TOF values due to redox processes of the bulk material interfering with HER currents. 

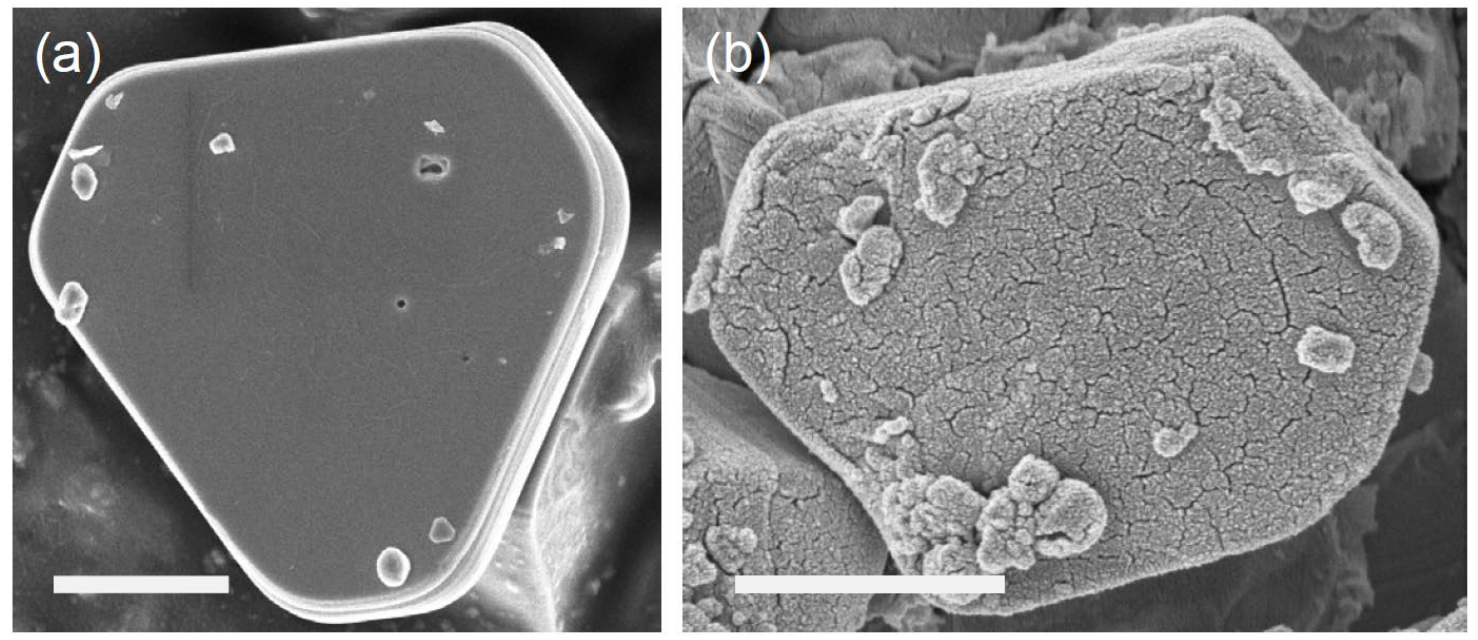

Figure S17. Comparison of the morphology of $\mathrm{Mo}_{2} \mathrm{C} T_{x}$ : $\mathrm{Co}$ (a) before and (b) after HER catalysis by SEM imaging. Scale bar is $1 \mu \mathrm{m}$.

\section{References}

(1) Deeva, E. B.; Kurlov, A.; Abdala, P. M.; Lebedev, D.; Kim, S. M.; Gordon, C. P.; Tsoukalou, A.; Fedorov, A.; Müller, C. R. In Situ XANES/XRD Study of the Structural Stability of Two-Dimensional Molybdenum Carbide $\mathrm{Mo}_{2} \mathrm{CT}_{\mathrm{x}}$ : Implications for the Catalytic Activity in the Water-Gas Shift Reaction. Chem. Mater. 2019, 31, 45054513.

(2) Le Bail, A. Whole Powder Pattern Decomposition Methods and Applications: A Retrospection. Powder Diffr. 2005, 20, 316-326.

(3) Rodríguez-Carvajal, J. Recent Advances in Magnetic Structure Determination by Neutron Powder Diffraction. Phys. B Condens. Matter 1993, 192, 55-69.

(4) Halim, J.; Kota, S.; Lukatskaya, M. R.; Naguib, M.; Zhao, M.-Q.; Moon, E. J.; Pitock, J.; Nanda, J.; May, S. J.; Gogotsi, Y.; et al. Synthesis and Characterization of 2D Molybdenum Carbide (MXene). Adv. Funct. Mater. 2016, 26, 3118-3127.

(5) Wei, C.; Rao, R. R.; Peng, J.; Huang, B.; Stephens, I. E. L.; Risch, M.; Xu, Z. J.; Shao-Horn, Y. Recommended Practices and Benchmark Activity for Hydrogen and Oxygen Electrocatalysis in Water Splitting and Fuel Cells. Adv. Mater. 2019, 31, 1806296.

(6) McCrory, C. C. L.; Jung, S.; Peters, J. C.; Jaramillo, T. F. Benchmarking Heterogeneous Electrocatalysts for the Oxygen Evolution Reaction. J. Am. Chem. Soc. 2013, 135, 16977-16987.

(7) Kresse, G.; Furthmüller, J. Efficient Iterative Schemes for Ab Initio Total-Energy Calculations Using a PlaneWave Basis Set. Phys. Rev. B 1996, 54, 11169-11186.

(8) Kresse, G.; Furthmüller, J. Efficiency of Ab-Initio Total Energy Calculations for Metals and Semiconductors Using a Plane-Wave Basis Set. Comput. Mater. Sci. 1996, 6, 15-50.

(9) Kresse, G.; Joubert, D. From Ultrasoft Pseudopotentials to the Projector Augmented-Wave Method. Phys. Rev. $B$ 1999, 59, 1758-1775.

(10) Perdew, J. P.; Burke, K.; Ernzerhof, M. Generalized Gradient Approximation Made Simple. Phys. Rev. Lett. 1996, 77, 3865-3868.

(11) Ling, C.; Shi, L.; Ouyang, Y.; Chen, Q.; Wang, J. Transition Metal-Promoted $\mathrm{V}_{2} \mathrm{CO}_{2}$ (MXenes): A New and Highly Active Catalyst for Hydrogen Evolution Reaction. Adv. Sci. 2016, 3, 1600180. 